\title{
Obesity and Physical Activity
}

\author{
Bo-Yeon Kim*, Dug-Hyun Choi, Chan-Hee Jung, Sung-Koo Kang, Ji-Oh Mok, Chul-Hee Kim \\ Division of Endocrinology \& Metabolism, Department of Internal Medicine, College of Medicine, Soonchunhyang University Bucheon Hospital, Bucheon, Korea
}

Some clinical manifestations of obesity include nonalcoholic fatty liver disease, type 2 diabetes, and cardiovascular disease. Calorie restriction may aid in weight loss in the short term. Exercise and physical activity are other means of weight loss. However, the efficacy of exercise and physical activity in weight reduction in obese populations is still unknown. In this review, we discuss the effects of exercise and physical activity in obese and overweight populations. We also discuss the effects of aerobic exercise and/or resistance training in weight loss and maintenance.

Key words: Obesity, Exercise, Physical activity, Weight loss, Weight maintenance
Received February 13, 2017

Reviewed March 4, 2017

Accepted March 17, 2017

${ }^{*}$ Corresponding author

Bo-Yeon Kim

http://orcid.org/0000-0002-3658-2351

Division of Endocrinology \& Metabolism, Department of Internal Medicine, College of Medicine, Soonchunhyang University Bucheon Hospital 170 Jomaru-ro, Wonmi-gu, Bucheon 14584, Korea

Tel: +82-32-621-5157

Fax: +82-32-621-5018

E-mail: byby815@schmc.ac.kr

\section{INTRODUCTION}

In Korea, the prevalence of obesity has steadily increased from $28.7 \%$ in 2006 to $32.4 \%$ in 2015 , as has the prevalence of abdominal obesity, from $18.3 \%$ in 2009 to $20.8 \%$ in $2015 .^{1}$ The clinical manifestations of obesity include nonalcoholic fatty liver disease ${ }^{2}$, type 2 diabetes ${ }^{3-5}$, and cardiovascular disease. ${ }^{6}$ Obese individuals have an increased risk of all-cause mortality. ${ }^{7-9}$ The American College of Cardiology/American Heart Association Task Force on Practice Guidelines and The Obesity Society (AHA/ACC/TOS) guidelines recommend a loss of 3-5\% of initial body weight for the management of obesity in adults. ${ }^{10}$ A negative energy balance is an important strategy in weight reduction. ${ }^{11}$ Calorie restriction may aid in weight loss in the short term. However, physical activity is important for weight loss because physical activity increases the metabolic rate, which results in increased energy expenditure and thus, negative energy balance. ${ }^{12}$ Given the association between obesity and physical inactivity, the 2013 AHA/ACC/TOS guideline for the management of overweight and obesity in adults recommended an increased physical activity of $\geq 150 \mathrm{~min} /$ week. $^{10}$ However, the efficacy of exercise and physical activity in weight reduction in obese individuals is not yet established.

In this review, we will discuss the effects of various types of exercises and physical activities in obese and overweight populations.

\section{Aerobic exercise interventions without calorie restriction}

Aerobic exercise (AE) is a popular intervention for the management of obesity and overweight. Several reviews and meta-analyses on effects of $\mathrm{AE}$ interventions on weight loss have been published. In a recent systematic review and meta-analysis, Thorogood et al. ${ }^{13}$ evaluated the efficacy of AE in obese individuals. They pooled the results of the 6 months and 12 months programs. Six-month exer- 
cise interventions effected a modest weight reduction of $1.6 \mathrm{~kg}$ (95\% CI, 1.56 to 1.64). Twelve-month $\mathrm{AE}$ interventions resulted in a weight reduction of $1.7 \mathrm{~kg}$ (95\% CI, 1.11 to 2.29) and a decrease in waist circumference of $1.95 \mathrm{~cm}$ (95\% CI, 0.29 to 3.62). Furthermore, isolated moderate-intensity AE interventions yielded a modest improvement in blood pressure and lipid levels. Exercise methodology, intensity, and frequency varied across the included trials. However, the results of this meta-analysis showed that isolated moderate-intensity $\mathrm{AE}$ interventions of 6-12 months result in modest weight loss in obese and overweight populations.

Another randomized controlled trial conducted in Japan included obese participants who had two or more risk factors for cardiovascular disease. ${ }^{14}$ All participants underwent a health counseling. The intervention group exercised 2-4 times a week for 6 months. This group showed significant reductions in body weight $(-1.60$ $\mathrm{kg})$, waist circumference $(-1.8 \mathrm{~cm})$, triglyceride levels, and highsensitivity C-reactive protein levels. Exercise interventions for 6 months also improved the cardiovascular risk profile of the participants. Our review of several studies suggests that $\mathrm{AE}$ interventions of 6-12 months without calorie restriction yield a 2-3\% loss in initial body weight, a finding corroborated by several trials (Table 1). In fact, even a modest weight loss of less than $3 \%$, when achieved via lifestyle-based strategies that include an increase in physical activity, have health benefits similar to greater weight loss without exercise. ${ }^{15}$ The relationship between anaerobic exercise volume and the extent of weight loss is an important factor. Moderate AE of 6

Table 1. Comparisons of the effects of exercise and physical activity in weight management

\begin{tabular}{|c|c|c|c|c|c|}
\hline & $\begin{array}{l}\text { Duration of } \\
\text { intervention } \\
\text { (month) }\end{array}$ & $\begin{array}{c}\text { Weight } \\
\text { change (\%) }\end{array}$ & $\begin{array}{l}\text { Waist } \\
\text { (cm) }\end{array}$ & $\begin{array}{l}\text { Body } \\
\text { fat }(\%)\end{array}$ & $\begin{array}{c}\text { Lean } \\
\text { mass } \\
(\%)\end{array}$ \\
\hline AE without $C R$ & $6-12$ & $\begin{array}{c}2-3 \% \downarrow \\
\text { (moderate intensity AE) } \\
>5 \% \downarrow \\
\text { (high intensity AE) }\end{array}$ & $\downarrow$ & $\downarrow$ & \\
\hline RT without CR & $6-12$ & $\mathrm{NC}, \uparrow$ & $\downarrow$ & $\downarrow$ & $\uparrow$ \\
\hline CR with PA & $6-12$ & $\begin{array}{c}3-5 \% \downarrow \\
\text { (moderate intensity } \\
\text { interventions) } \\
>5 \% \downarrow \\
\text { (high intensity } \\
\text { interventions) }\end{array}$ & $\downarrow$ & $\downarrow$ & \\
\hline
\end{tabular}

$A E$, aerobic exercise; $R T$, resistance training; $C R$, calorie restriction; $N C$, no change; $P A$, physical activity. months without calorie restriction typically showed a 2-3\% weight loss. ${ }^{14,16}$ However, high intensity and frequent exercise seem to predict a greater weight loss outcome. For example, in the studies conducted by Nishijima et al. ${ }^{14}$ and Alves et al. ${ }^{16}$, the intervention groups performed a moderate intensity exercise intervention lasting for $40 \mathrm{~min} /$ day at a frequency of 2-4 times a week. The mean weight loss was 1.59 and $1.69 \mathrm{~kg}$, respectively. In the Midwest exercise trial $2^{17}$, a weight loss of $>5 \%$ was achieved (Table 1 ). This randomized, controlled trial compared the effects of three different volumes of $\mathrm{AE}$ without calorie restriction. All participants in the exercise intervention groups attended exercise at a frequency of five times a week. The 400 and $600 \mathrm{kcal} /$ day exercise groups showed weight reductions of 4.3 and $5.7 \%$, respectively. Lee et al. ${ }^{18}$ reported that an extremely high intensity exercise intervention lasting 20 weeks resulted in a $12.5 \mathrm{~kg}$ weight loss in young men (aged 17-19 years). We suggest a dose-dependent relationship between AE intensity and weight loss.

\section{Resistance exercise interventions without calorie restriction}

$\mathrm{AE}$ reduces fat mass but has little effect on maintenance of fat-free mass. ${ }^{19-22}$ Resistance training (RT), which yields fat-free mass gain, increases resting energy expenditure. ${ }^{23-25}$ However, studies on the effect of RT in weight loss are lacking. In 2008, Willis et al. ${ }^{26}$, in their randomized trial, reported the effects of aerobic and/or resistance exercise on body and fat mass. They compared the effects of AE, $\mathrm{RT}$, and a combination of $\mathrm{AE}$ and $\mathrm{RT}(\mathrm{AE} / \mathrm{RT})$ in weight loss and weight maintenance. Participants were randomized into three groups (AE, RT, and $\mathrm{AE} / \mathrm{RT}$ ), and the interventions were performed for 8 months. Significant weight loss was seen in both AE and AE/RT groups; in contrast, weight gain was seen in the RT group (Table 1). All groups had significant reductions in waist circumference and fat mass and significant increases in $\mathrm{VO}_{2}$ max. The $\mathrm{RT}$ and $\mathrm{AE} / \mathrm{RT}$ groups showed significant increases in fat-free mass and thigh muscle compared with the baseline. Only the RT group did not achieve weight loss. In another trial ${ }^{27}$, participants (mean body mass index [BMI $] 31.4 \mathrm{~kg} / \mathrm{m}^{2}$, mean age 22 years) were randomized into RT and control groups. After 12 weeks of intervention, the RT group had a mean body weight gain compared with the baseline (Table 1). The RT group participants also had in- 
creased muscle strength and fat-free mass and decreased total and trunk fat mass compared with the baseline. RT without calorie restriction improves body composition, but may not yield weight loss (Table 1). Moghadasi et al. ${ }^{28}$ conducted a randomized trial to examine the effect of RT in obese men. Participants were randomized to RT or control groups. After 8 weeks of intervention, the RT group had improved body composition, but no weight loss. The RT group showed significant body fat loss and improvement in biomarkers related to glucose metabolism. In a systematic review on the effect of RT in obese populations, authors reported that RT alone does not cause significant weight loss, but RT with dietary calorie restriction may reduce weight by $4.775 \mathrm{~kg} .{ }^{29}$ In summary, RT without calorie restriction may not yield significant weight loss. However, RT, by improving body composition, results in many health benefits.

\section{Combined calorie restriction and physical activity interventions}

Calorie restriction and exercise intervention are common strategies for weight loss in obese individuals. However, optimal lifestyle habits in interventions are debated. Calorie restriction can result in a negative energy balance and thus weight loss. Various diet regimens such as low-calorie and calorie-restricted diets and low-carbohydrate diets are used for weight loss. In general, in various diet and exercise studies, energy intake was $500 \mathrm{kcal}$ or more less than estimated energy need and fat intake was less than $30 \%$ of total energy intake. Franz et al. ${ }^{30}$ conducted a meta-analysis of randomized controlled trials including obese and overweight participants who underwent one of several weight loss interventions (diet alone, diet and exercise, exercise alone, meal replacements, very-low-energy diets, weight-loss medications, and advice alone). Pooled mean weight loss in the combined diet + exercise group was $7.8 \pm 5.2 \mathrm{~kg}$. However, the mean weight loss was $3.7 \pm 4.3 \mathrm{~kg}$ in the diet-only control group. ${ }^{30}$ In 2009, Wu et al. ${ }^{31}$ conducted another meta-analysis which systematically reviewed the effect of 6-12 months combined diet + exercise interventions and diet-only interventions on weight loss in obese individuals. The combined diet + exercise intervention showed a greater long-term weight loss than the dietonly intervention. In a pooled analysis of 10 randomized trials, the diet-only intervention yielded a weight loss of $1.78 \mathrm{~kg}$, while the diet + exercise combined intervention yielded a weight loss of 3.6 $\mathrm{kg}$. However, partial weight regain was seen in both diet-only and diet + exercise groups. Because of weight regain, prolonged diet and exercise interventions may be important. In another- study, a combined diet+exercise intervention resulted in greater weight loss than a diet-only intervention in obese postmenopausal women. ${ }^{32}$ This study compared the effects of lifestyle interventions on body weight and composition in overweight to obese postmenopausal women; 439 participants were randomized into four groups (moderate to high intensity aerobic exercise, dietary calorie restriction, both interventions combined, and no lifestyle change). All intervention groups had significant weight losses. The mean weight loss in the diet group, exercise group, and diet + exercise groups was 7.1 $\mathrm{kg}, 2.0 \mathrm{~kg}$, and $8.9 \mathrm{~kg}$, respectively. Moreover, over a 1-year period, all interventions improved adiposity (Table 1), with greatest improvement seen in the diet + exercise intervention. In almost all studies, the diet + exercise combined intervention resulted in at least at $3-5 \%$ or higher weight loss (Table 1). The MONET study however showed contrasting results. ${ }^{33}$ This study also targeted postmenopausal women $(\mathrm{n}=173)$. Participants were divided into two groups (only diet vs diet $+\mathrm{RT}$ ). This study found equivalent weight loss between the groups. Depending on the type of exercise intervention, the effect on weight may differ. Unlike diet alone, exercise helps maintaining lean body mass, and this could have important implications in older individuals who are at increased risk of sarcopenia. Greater adherence to lifestyle intervention has been shown to reduce weight and improve body composition. Greater adherence to the exercise interventions in both the DPP and the Look AHEAD trials was associated with higher rates of achieving weight loss. ${ }^{34,35}$ Alhassan et al..$^{36}$ reported that adherence to diet was a key correlate of weight loss across various diet regimens.

Nevertheless, the combined diet + exercise interventions were found to be superior to diet-only interventions in weight reduction. However, both diet-only and diet + exercise combined interventions are associated with long-term weight regain, and future trials should explore better interventions to limit weight regain and induce greater weight loss.

\section{Increasing physical activity in daily life}

Due to westernization of diet and lack of physical activity, the prevalence of obesity is continuously increasing. ${ }^{37}$ In order to im- 
prove obesity, it is very important to reduce the amount of energy intake and increase the amount of energy expenditure, and it is very difficult for busy adults to exercise regularly. Therefore, we would like to introduce "Non Exercise Activity Thermogenesis" (NEAT) that can be induced energy consumption in daily life. Physical activity refers to all movements caused by skeletal muscles that cause energy consumption and it is classified into occupational physical activity and leisure physical activity. Exercise is a sub-concept of this physical activity and is included in leisure physical activity and it is defined as a structured activity that is planned and repeated. ${ }^{38}$ The total daily energy expenditure of humans consists of basic metabolic rate (BMR), thermogenic effect of food (TEF), and activity thermogenesis (AT). BMR accounts for $60 \%$ of total daily energy expenditure, and TEF accounts for $10 \%$ of total daily energy expenditure. AT varies greatly between individuals, from about $15 \%$ for static individuals to $50 \%$ for dynamic individuals. ${ }^{39}$ AT is divided into exercise activity thermogenesis (EAT) and NEAT. NEAT is energy consumed through physical activities such as sitting, standing, walking, speaking, and restlessness, which are unlike planned and structured $\mathrm{EAT}^{40}$ As a result of the analysis of the NEAT of obese and lean people, sitting time was 571 minutes for the obese people and longer than 407 minutes for the lean people. Walking time was shorter in obese people. It is $269-477 \mathrm{kcal}$ per day converting the difference to calories. Therefore, it is assumed that the daily intake is maintained at the same level, and if the posture and the gait pattern of the lean people are applied to the obese people, additive energy consumption of about $350 \mathrm{kcal}$ per day may occur and prevent body weight gain. ${ }^{41,42}$ NEAT as moving the body, walking, climbing stairs was more than 100 times higher than energy expenditure of resting. In another study, the participants had to do dishes themselves, walk to work, walk up the stairs instead of the elevator, resulting in a consumption of about $120 \mathrm{kcal}$ per day. ${ }^{43}$ Increasing NEAT and lifestyle change will prevent further weight gain, even if there is not much weight loss. Increasing physical activity in daily life can be effective in managing weight as much as regular exercise.

\section{Effects on maintenance of weight loss of physical activity}

Most obese individuals do not maintain weight loss for long periods. ${ }^{44,45}$ Weight changes are affected by energy balance. ${ }^{46}$ If the energy expenditure remains low, weight gain will occur. Several studies have reported that declines in physical activity both in occupation and leisure may have an important role in the increase in obesity rates in the recent years. ${ }^{47,48}$ Furthermore, many studies suggest that physical activity has an important role in weight gain. ${ }^{49,50}$ High physical activity levels is inversely associated with cardiovascular disease, type 2 diabetes and all-cause mortality regardless of weight loss ${ }^{51,52}$ and strongly associated with no weight regain over 1 year. ${ }^{53,54}$ The American College of Sports Medicine recommended 200-300 $\mathrm{min} /$ week of moderate physical activity to prevent weight regain after weight loss. ${ }^{51}$ Saris et al..$^{55}$ recommended that physical activity levels of 225-300 $\mathrm{min} /$ week were necessary to prevent the transition from normal weight to obese. The recommended physical activity time to prevent weight regain is more than the recommended time for improving health. ${ }^{51}$ Hunter et al. ${ }^{56}$ reported a randomized trial to evaluate the effect of exercise on weight loss maintenance. In this trial, 208 women (BMI range, 27 to $30 \mathrm{~kg} / \mathrm{m}^{2}$ ) were recruited. During the weight loss phase, all subjects were instructed to remain on the $800 \mathrm{kcal} /$ day diet until a BMI of $<25 \mathrm{~kg} / \mathrm{m}^{2}$ was achieved. In addition, the subjects were randomly assigned to three groups: $\mathrm{AE}$ with diet, $\mathrm{RT}$ with diet and diet only (non-exercise group). The subjects were followed-up after one year. Weight gain among the adherers in both the AE and RT groups was significantly less compared with that among the $\mathrm{AE}$ non-adherers, RT non-adherers and the non-exercise group. Weight gains among the adherers in the $\mathrm{AE}$ and $\mathrm{RT}$ groups were $3.1 \mathrm{~kg}$ and $3.9 \mathrm{~kg}$, respectively. No significant differences were observed between the $\mathrm{AE}$ and RT groups. Weight gain in non-exercise group was $6.4 \mathrm{~kg}$. In addition, in the $\mathrm{AE}$ and $\mathrm{RT}$ groups visceral fat did not significantly increase $(<0.8 \%)$ as compared with that in the non-exercise group (38\%). This study suggests that the AE and RT interventions may prevent weight regain during weight maintenance phase and prevent regain of harmful visceral fat. Individuals who lose weight below expectations based on energy expenditure have been termed "weight compensator." Several studies examined weight compensation after aerobic exercise training. ${ }^{57,58}$ In a large exercise intervention trial among postmenopausal women, the difference between actual weight loss and predicted weight loss (compensation) increased with exercise dose. ${ }^{57}$ Weight maintenance may be affected by weight compensation. This explains individual differences in weight loss or weight maintenance. 
In summary, most obese individuals do not maintain the loss for long periods. The recommendations for physical activity to prevent weight regain after weight loss was 200-300 min/week of moderate physical activity. Not only AE but also RT may hinder weight regain during weight maintenance. In addition, we need to consider "weight compensation" to explain the individual differences in weight loss or weight maintenance.

\section{CONCLUSION}

Our literature review suggests that $\mathrm{AE}$ interventions of 6-12 months without diet intervention yield a 2-3\% loss in initial body weight and a dose-response relationship exists between $\mathrm{AE}$ intensity and weight loss. RT without dietary calorie restriction may not yield significant weight loss. However, RT improves body composition and thus yields many health benefits, and RT combined with a dietary calorie restriction can induce weight loss. The diet + exercise combined intervention is superior to diet-only interventions in inducing weight loss. However, most obese individuals do not maintain weight loss for long periods and both diet-only and diet + exercise combined interventions are associated with long-term weight regain. Moderate physical activity prevents weight regain after weight loss. Not only AE but also RT may hinder weight regain. Increasing physical activity in daily life can be effective in managing weight as much as regular exercise. Future trials should explore better interventions to limit weight regain and induce greater weight loss.

\section{CONFLICTS OF INTEREST}

The authors declare no conflict of interest.

\section{ACKNOWLEDGMENTS}

This work was supported by the Soonchunhyang University Research Fund.

\section{REFERENCES}

1. Korean Society for the Study of Obesity. Obesity Fact Sheet 2016. Seoul: Korean Society for the Study of Obesity; 2016.
Available from: URL: http://www.kosso.or.kr/main.html

2. Fabbrini E, Sullivan S, Klein S. Obesity and nonalcoholic fatty liver disease: biochemical, metabolic, and clinical implications. Hepatology 2010;51:679-89.

3. Asia Pacific Cohort Studies Collaboration, Ni Mhurchu C, Parag V, Nakamura M, Patel A, Rodgers A, et al. Body mass index and risk of diabetes mellitus in the Asia-Pacific region. Asia Pac J Clin Nutr 2006;15:127-33.

4. Hartemink N, Boshuizen HC, Nagelkerke NJ, Jacobs MA, van Houwelingen HC. Combining risk estimates from observational studies with different exposure cutpoints: a meta-analysis on body mass index and diabetes type 2. Am J Epidemiol 2006; 163:1042-52.

5. Abdullah A, Peeters A, de Courten M, Stoelwinder J. The magnitude of association between overweight and obesity and the risk of diabetes: a meta-analysis of prospective cohort studies. Diabetes Res Clin Pract 2010;89:309-19.

6. Lu Y, Hajifathalian K, Ezzati M, Woodward M, Rimm EB, Danaei G. Metabolic mediators of the effects of body-mass index, overweight, and obesity on coronary heart disease and stroke: a pooled analysis of 97 prospective cohorts with 1.8 million participants. Lancet 2014;383:970-83.

7. Berrington de Gonzalez A, Hartge P, Cerhan JR, Flint AJ, Hannan L, MacInnis RJ, et al. Body-mass index and mortality among 1.46 million white adults. N Engl J Med 2010;363: 2211-9.

8. Flegal KM, Kit BK, Orpana H, Graubard BI. Association of all-cause mortality with overweight and obesity using standard body mass index categories: a systematic review and metaanalysis. JAMA 2013;309:71-82.

9. Davey Smith G, Sterne JA, Fraser A, Tynelius P, Lawlor DA, Rasmussen F. The association between BMI and mortality using offspring BMI as an indicator of own BMI: large intergenerational mortality study. BMJ 2009;339:b5043.

10. Jensen MD, Ryan DH, Apovian CM, Ard JD, Comuzzie AG, Donato KA, et al. 2013 AHA/ACC/TOS guideline for the management of overweight and obesity in adults: a report of the American College of Cardiology/American Heart Association Task Force on Practice Guidelines and The Obesity Society. Circulation 2014;129(25 Suppl 2):S102-38. 
11. Spiegelman BM, Flier JS. Obesity and the regulation of energy balance. Cell 2001;104:531-43.

12. van Baak MA. Physical activity and energy balance. Public Health Nutr 1999;2:335-9.

13. Thorogood A, Mottillo S, Shimony A, Filion KB, Joseph L, Genest J, et al. Isolated aerobic exercise and weight loss: a systematic review and meta-analysis of randomized controlled trials. Am J Med 2011;124:747-55.

14. Nishijima H, Satake K, Igarashi K, Morita N, Kanazawa N, Okita K. Effects of exercise in overweight Japanese with multiple cardiovascular risk factors. Med Sci Sports Exerc 2007; 39:926-33.

15. Ross R, Blair S, de Lannoy L, Després JP, Lavie CJ. Changing the endpoints for determining effective obesity management. Prog Cardiovasc Dis 2015;57:330-6.

16. Alves JG, Gale CR, Mutrie N, Correia JB, Batty GD. A 6-month exercise intervention among inactive and overweight favela-residing women in Brazil: the Caranguejo Exercise Trial. Am J Public Health 2009;99:76-80.

17. Donnelly JE, Honas JJ, Smith BK, Mayo MS, Gibson CA, Sullivan DK, et al. Aerobic exercise alone results in clinically significant weight loss for men and women: midwest exercise trial 2. Obesity (Silver Spring) 2013;21:E219-28.

18. Lee L, Kumar S, Leong LC. The impact of five-month basic military training on the body weight and body fat of 197 moderately to severely obese Singaporean males aged 17 to 19 years. Int J Obes Relat Metab Disord 1994;18:105-9.

19. Garrow JS, Summerbell CD. Meta-analysis: effect of exercise, with or without dieting, on the body composition of overweight subjects. Eur J Clin Nutr 1995;49:1-10.

20. van Dale D, Saris WH. Repetitive weight loss and weight regain: effects on weight reduction, resting metabolic rate, and lipolytic activity before and after exercise and/or diet treatment. Am J Clin Nutr 1989;49:409-16.

21. Whatley JE, Gillespie WJ, Honig J, Walsh MJ, Blackburn AL, Blackburn GL. Does the amount of endurance exercise in combination with weight training and a very-low-energy diet affect resting metabolic rate and body composition? Am J Clin Nutr 1994;59:1088-92.

22. Hill JO, Sparling PB, Shields TW, Heller PA. Effects of exer- cise and food restriction on body composition and metabolic rate in obese women. Am J Clin Nutr 1987;46:622-30.

23. Treuth MS, Hunter GR, Weinsier RL, Kell SH. Energy expenditure and substrate utilization in older women after strength training: 24-h calorimeter results. J Appl Physiol (1985) 1995; $78: 2140-6$.

24. Hunter GR, Wetzstein CJ, Fields DA, Brown A, Bamman MM. Resistance training increases total energy expenditure and free-living physical activity in older adults. J Appl Physiol (1985) 2000;89:977-84.

25. Pratley R, Nicklas B, Rubin M, Miller J, Smith A, Smith M, et al. Strength training increases resting metabolic rate and norepinephrine levels in healthy 50- to 65-yr-old men. J Appl Physiol (1985) 1994;76:133-7.

26. Willis LH, Slentz CA, Bateman LA, Shields AT, Piner LW, Bales CW, et al. Effects of aerobic and/or resistance training on body mass and fat mass in overweight or obese adults. J Appl Physiol (1985) 2012;113:1831-7.

27. Roberts CK, Croymans DM, Aziz N, Butch AW, Lee CC. Resistance training increases SHBG in overweight/obese, young men. Metabolism 2013;62:725-33.

28. Moghadasi M, Abdollahpur N, Abdehgah EB, Hosseini F, Hosseini SA. Effect of eight weeks resistance training on adipocyte fatty acid-binding protein in obese middle-aged men. Int J Sport Studies 2014;4:1198-204.

29. Clark JE, Goon DT. The role of resistance training for treatment of obesity related health issues and for changing health status of the individual who is overfat or obese: a review. J Sports Med Phys Fitness 2015;55:205-22.

30. Franz MJ, VanWormer JJ, Crain AL, Boucher JL, Histon T, Caplan W, et al. Weight-loss outcomes: a systematic review and meta-analysis of weight-loss clinical trials with a minimum 1-year follow-up. J Am Diet Assoc 2007;107:1755-67.

31. Wu T, Gao X, Chen M, van Dam RM. Long-term effectiveness of diet-plus-exercise interventions vs. diet-only interventions for weight loss: a meta-analysis. Obes Rev 2009;10:313-23.

32. Foster-Schubert KE, Alfano CM, Duggan CR, Xiao L, Campbell KL, Kong A, et al. Effect of diet and exercise, alone or combined, on weight and body composition in overweight-toobese postmenopausal women. Obesity (Silver Spring) 2012; 
20:1628-38.

33. Messier V, Rabasa-Lhoret R, Doucet E, Brochu M, Lavoie JM, Karelis A, et al. Effects of the addition of a resistance training programme to a caloric restriction weight loss intervention on psychosocial factors in overweight and obese post-menopausal women: a Montreal Ottawa New Emerging Team study. J Sports Sci 2010;28:83-92.

34. Wadden TA, West DS, Neiberg RH, Wing RR, Ryan DH, Johnson KC, et al. One-year weight losses in the Look AHEAD study: factors associated with success. Obesity (Silver Spring) 2009; 17:713-22.

35. Wing RR, Hamman RF, Bray GA, Delahanty L, Edelstein SL, Hill JO, et al. Achieving weight and activity goals among diabetes prevention program lifestyle participants. Obes Res 2004; 12:1426-34.

36. Alhassan S, Kim S, Bersamin A, King AC, Gardner CD. Dietary adherence and weight loss success among overweight women: results from the A TO Z weight loss study. Int J Obes (Lond) 2008;32:985-91.

37. Resnick HE, Valsania P, Halter JB, Lin X. Relation of weight gain and weight loss on subsequent diabetes risk in overweight adults. J Epidemiol Community Health 2000;54:596-602.

38. Caspersen CJ, Powell KE, Christenson GM. Physical activity, exercise, and physical fitness: definitions and distinctions for health-related research. Public Health Rep 1985;100:126-31.

39. Donahoo WT, Levine JA, Melanson EL. Variability in energy expenditure and its components. Curr Opin Clin Nutr Metab Care 2004;7:599-605.

40. Levine JA. Nonexercise activity thermogenesis (NEAT): environment and biology. Am J Physiol Endocrinol Metab 2004; 286:E675-85.

41. Levine JA, Baukol PA, Westerterp KR. Validation of the Tracmor triaxial accelerometer system for walking. Med Sci Sports Exerc 2001;33:1593-7.

42. Levine JA, Lanningham-Foster LM, McCrady SK, Krizan AC, Olson LR, Kane PH, et al. Interindividual variation in posture allocation: possible role in human obesity. Science 2005;307: 584-6.

43. Lanningham-Foster L, Nysse LJ, Levine JA. Labor saved, calories lost: the energetic impact of domestic labor-saving devic- es. Obes Res 2003;11:1178-81.

44. Wadden TA. Treatment of obesity by moderate and severe caloric restriction. Results of clinical research trials. Ann Intern Med 1993;119:688-93.

45. Anderson JW, Konz EC, Frederich RC, Wood CL. Long-term weight-loss maintenance: a meta-analysis of US studies. Am J Clin Nutr 2001;74:579-84.

46. Thomas DM, Bouchard C, Church T, Slentz C, Kraus WE, Redman LM, et al. Why do individuals not lose more weight from an exercise intervention at a defined dose? An energy balance analysis. Obes Rev 2012;13:835-47.

47. Church TS, Thomas DM, Tudor-Locke C, Katzmarzyk PT, Earnest CP, Rodarte RQ, et al. Trends over 5 decades in U.S. occupation-related physical activity and their associations with obesity. PLoS One 2011;6:e19657.

48. Lee IM, Djoussé L, Sesso HD, Wang L, Buring JE. Physical activity and weight gain prevention. JAMA 2010;303:1173-9.

49. Donnelly JE, Blair SN, Jakicic JM, Manore MM, Rankin JW, Smith BK. Appropriate physical activity intervention strategies for weight loss and prevention of weight regain for adults. Med Sci Sports Exerc 2009;41:459-71.

50. Fogelholm M, Kukkonen-Harjula K. Does physical activity prevent weight gain--a systematic review. Obes Rev 2000;1:95111.

51. Haskell WL, Lee IM, Pate RR, Powell KE, Blair SN, Franklin BA, et al. Physical activity and public health: updated recommendation for adults from the American College of Sports Medicine and the American Heart Association. Med Sci Sports Exerc 2007;39:1423-34.

52. Swift DL, Lavie CJ, Johannsen NM, Arena R, Earnest CP, O'Keefe JH, et al. Physical activity, cardiorespiratory fitness, and exercise training in primary and secondary coronary prevention. Circ J 2013;77:281-92.

53. Weinsier RL, Hunter GR, Desmond RA, Byrne NM, Zuckerman PA, Darnell BE. Free-living activity energy expenditure in women successful and unsuccessful at maintaining a normal body weight. Am J Clin Nutr 2002;75:499-504.

54. Schoeller DA, Shay K, Kushner RF. How much physical activity is needed to minimize weight gain in previously obese women? Am J Clin Nutr 1997;66:551-6. 
55. Saris WH, Blair SN, van Baak MA, Eaton SB, Davies PS, Di Pietro $\mathrm{L}$, et al. How much physical activity is enough to prevent unhealthy weight gain? Outcome of the IASO 1st Stock Conference and consensus statement. Obes Rev 2003;4:101-14.

56. Hunter GR, Brock DW, Byrne NM, Chandler-Laney PC, Del Corral P, Gower BA. Exercise training prevents regain of visceral fat for 1 year following weight loss. Obesity (Silver Spring) 2010;18:690-5.

57. Church TS, Martin CK, Thompson AM, Earnest CP, Mikus
CR, Blair SN. Changes in weight, waist circumference and compensatory responses with different doses of exercise among sedentary, overweight postmenopausal women. PLoS One 2009;4:e4515.

58. King NA, Hopkins M, Caudwell P, Stubbs RJ, Blundell JE. Individual variability following 12 weeks of supervised exercise: identification and characterization of compensation for exercise-induced weight loss. Int J Obes (Lond) 2008;32:177-84. 